\title{
Bridge Risk Assessment Using a Hybrid AHP/DEA Methodology
}

\author{
Yingming Wang ${ }^{1}$ Jun Liu $^{2}$ Taha M S Elhag ${ }^{3}$ Luis Martínez López $^{4}$ \\ ${ }^{1}$ Department of Manufacturing Engineering and Engineering Management, City University of Hong Kong \\ 83 Tat Chee Avenue, Kowloon Tong, Hong Kong \\ ${ }^{2}$ School of Computing and Mathematics, Faculty of Engineering, University of Ulster at Jordanstown \\ Shore Road, Newtownabbey, Co. Antrim BT37 0QB, Northern Ireland, UK \\ ${ }^{3}$ School of Mechanical, Aerospace and Civil Engineering, The University of Manchester \\ PO Box 88, Manchester M60 1QD, UK \\ ${ }^{4}$ Department of Computer Science, University of Jaén, E-23071 Jaén, Spain
}

\begin{abstract}
The traditional analytic hierarchy process (AHP) method can only compare a very limited number of decision alternatives. When there are hundreds or thousands of alternatives to be compared, the pairwise comparison manner is obviously infeasible. In this paper we propose a hybrid AHP/DEA methodology to facilitate the risk assessment of hundreds or thousands of bridge structures, where pairwise comparisons are impossible.
\end{abstract}

Keywords: Bridge risk assessment, Analytic hierarchy process, Data envelopment analysis

\section{Introduction}

Bridge risk assessment is often conducted to determine the priority of bridge structures for maintenance and is essentially a multiple criteria decision making (MCDM) problem, which involves multiple assessment criteria such as safety, functionality, sustainability and so on. Therefore, MCDM approaches can be used for bridge risk assessment.

Of the MCDM approaches, the analytic hierarchy process (AHP) method [1] is particularly suitable for modeling qualitative criteria and has found extensive applications in a wide variety of areas such as selection, evaluation, planning and development, decision making, forecasting, and so on [2]. However, due to the fact that there are hundreds or thousands of bridge structures to be evaluated and prioritized at a time, while the AHP method can only compare a very limited number of decision alternatives, the pairwise comparison manner is obviously infeasible in this situation. To overcome this difficulty, we combine the AHP with the data envelopment analysis (DEA) [3] and present a hybrid AHP/DEA methodology for bridge risk assessment.
The paper is organized as follows. In Section 2, we propose a hybrid AHP/DEA methodology for MCDM problems with a large number of decision alternatives. Section 3 presents an application of the hybrid AHP/DEA methodology to bridge risk assessment, where 20 bridge structures are to be prioritized for maintenance. Conclusions are offered in Section 4.

\section{A hybrid AHP/DEA methodology}

The idea of combining the AHP and DEA is not new. There have been several attempts to integrate them in real applications. The interested reader may refer to [4]-[15] for details. However, none of them can be used for bridge risk assessment where hundreds or thousands of bridge structures need to be assessed and prioritized for maintenance and pairwise comparisons for so many bridge structures are certainly impossible.

To solve this problem, we develop a hybrid AHP/DEA methodology for bridge risk assessment, which is able to cope with any large number of bridge structures or decision alternatives.

Consider a generic MCDM problem with $m$ criteria $C_{1}, \ldots, C_{m}, n$ decision alternatives $A_{1}, \ldots, A_{n}$, and the weights of criteria $w_{1}, \ldots, w_{m}$ being determined by the AHP. For the $n$ decision alternatives, it is impossible to construct a pairwise comparison matrix with respect to each criterion when the number of decision alternatives is larger than 15.

On the one hand, a large number of pairwise comparisons will add heavy burden to experts and make them fed up with making comparisons. On the other hand, too many comparisons easily lead to conflict judgments and inconsistency. 
Table 1 Distributed decision matrix for decision alternatives

\begin{tabular}{|c|c|c|c|c|c|c|c|c|c|c|c|c|c|}
\hline \multirow[t]{3}{*}{ Alternative } & \multicolumn{13}{|c|}{ Decision criteria } \\
\hline & \multicolumn{4}{|c|}{$C_{1}$} & \multicolumn{4}{|c|}{$C_{2}$} & \multirow{2}{*}{$\begin{array}{l}\cdots \\
\cdots\end{array}$} & \multicolumn{4}{|c|}{$C_{m}$} \\
\hline & $H_{11}$ & $H_{12}$ & $\cdots$ & $H_{1 K_{1}}$ & $H_{21}$ & $H_{22}$ & $\cdots$ & $H_{2 K_{2}}$ & & $H_{m 1}$ & $H_{m 2}$ & $\cdots$ & $H_{m K_{m}}$ \\
\hline$\overline{A_{1}}$ & $m_{111}$ & $m_{112}$ & $\cdots$ & $m_{11 K_{1}}$ & $m_{121}$ & $m_{122}$ & $\cdots$ & $m_{12 K_{2}}$ & $\cdots$ & $m_{1 m 1}$ & $m_{1 m 2}$ & $\cdots$ & $m_{1 m K_{m}}$ \\
\hline$A_{2}$ & $m_{211}$ & $m_{212}$ & $\cdots$ & $m_{21 K_{1}}$ & $m_{221}$ & $m_{222}$ & $\cdots$ & $m_{22 K_{2}}$ & $\cdots$ & $m_{2 m 1}$ & $m_{2 m 2}$ & $\cdots$ & $m_{2 m K_{m}}$ \\
\hline$\vdots$ & $\vdots$ & $\vdots$ & $\cdots$ & $\vdots$ & $\vdots$ & $\vdots$ & $\cdots$ & $\vdots$ & $\cdots$ & $\vdots$ & $\vdots$ & $\cdots$ & $\vdots$ \\
\hline$A_{\mathrm{n}}$ & $m_{n 11}$ & $m_{n 12}$ & $\cdots$ & $m_{n 1 K_{1}}$ & $m_{n 21}$ & $m_{n 22}$ & $\cdots$ & $m_{n 2 K_{2}}$ & $\cdots$ & $m_{n m 1}$ & $m_{n m 2}$ & $\cdots$ & $m_{n m K_{m}}$ \\
\hline
\end{tabular}

To characterize the relative importance of decision alternatives with respect to each criterion, we define for each criterion a set of linguistic assessment grades: $G_{j}=\left\{H_{j 1}, \ldots, H_{j K_{j}}\right\}(j=1, \ldots, m)$, where $H_{j 1}, \ldots, H_{j K_{j}}$ represent the importance from the most to least important and $K_{j}$ is the number of assessment grades for criterion $j$. This definition allows for different criteria to be evaluated using different numbers of assessment grades and provides flexibility for setting up grades. We then ask the experts from different domains to assess the decision alternatives and classify them into their corresponding assessment grades. Take the criterion $\mathrm{j}$ for example. The assessment results can be characterized by $n$ distributed assessment vectors:

$$
R\left(C_{j}\left(A_{i}\right)\right)=\left\{\left(H_{j 1}, m_{i j 1}\right), \ldots,\left(H_{j K_{j}}, m_{i j K_{j}}\right)\right\}
$$

$i=1, \ldots, n$,

where $m_{i j k}\left(k=1, \ldots, K_{j}\right)$ are the numbers of the experts who assess the alternative $A_{i}$ to Grade $H_{j k}$ under the criterion $\mathrm{j}$. All the distributed assessment vectors form a distributed decision matrix, as shown in Table 1.

Let $s\left(H_{j k}\right)$ be the scoring of Grade $H_{j k}$ $\left(k=1, \ldots, K_{j}\right)$. Then, the local score of each alternative with respect to every criterion can be defined as

$$
v_{i j}=\sum_{k=1}^{K_{j}} m_{i j k} s\left(H_{j k}\right), i=1, \ldots, n ; j=1, \ldots, m .
$$

To determine the local score of each alternative with respect to every criterion, we view each alternative as a decision making unit (DMU), $s\left(H_{j k}\right)$ as the weight assigned to the output $m_{i j k}$, and construct the following DEA model with common weights:

Maximize $\alpha$

Subject to $\alpha \leq v_{i j}=\sum_{k=1}^{K_{j}} m_{i j k} s\left(H_{j k}\right) \leq 1$,

$i=1, \ldots, n$,

$$
s\left(H_{j 1}\right) \geq 2 s\left(H_{j 2}\right) \geq \cdots \geq K_{j} s\left(H_{j K_{j}}\right) \geq 0,
$$

where the second constraint is strong ordering condition imposed on assessment grades.

By solving the above model (3) for each criterion, the local scores of each alternative with respect to the $m$ decision criteria can all be generated and then can be aggregated into an overall score by using the following simple additive weighting (SAW) method [16]:

$$
V\left(A_{i}\right)=\sum_{j=1}^{m} w_{j} v_{i j}^{*}=\sum_{j=1}^{m} w_{j}\left(\sum_{k=1}^{K_{j}} m_{i j k} s^{*}\left(H_{j k}\right)\right),
$$

$i=1, \ldots, n$,

where $w_{j}(j=1, \ldots, m)$ are the criteria weights determined by the AHP, $s^{*}\left(H_{j k}\right)$ ( $j=1, \ldots, m ; k=1, \ldots, K_{j}$ ) are the optimal scorings of the assessment grades determined by model (3), and $V\left(A_{i}\right)(i=1, \ldots, n)$ are the overall scores of the $n$ alternatives, based on which the $n$ alternatives can be ranked or prioritized.

\section{Application to bridge risk assessment}

It is estimated that there are about 160,000 bridges in the UK. The limited annual budget of repair and maintenance calls for a priority scheme to select and schedule bridge structures for maintenance.

\subsection{Selection of assessment criteria and determination of their weights}

According to the British Highways Agency (2004) [17], the maintenance priorities of bridge structures are determined by their risks, which are assessed in terms of four decision criteria: safety, functionality, sustainability, and environment. As an illustration, 20 bridge structures considered here shown in Fig.1. 


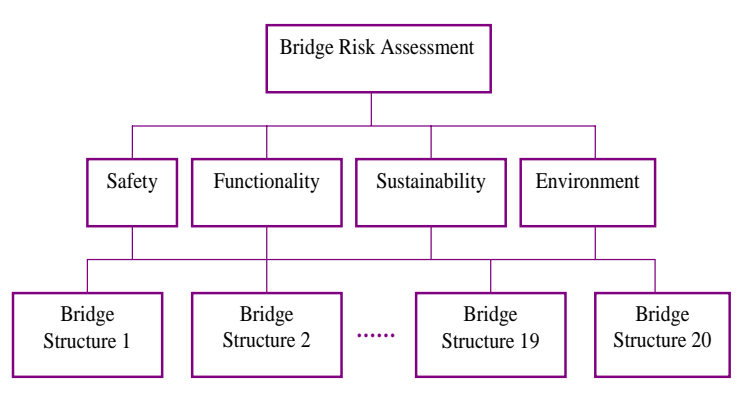

Fig. 1. Hierarchical structure for bridge risk assessment

The weights of criteria are assumed to be determined by the following pairwise comparison matrix:

$$
A=\left[\begin{array}{llll}
1 & 2 & 3 & 5 \\
1 / 2 & 1 & 2 & 3 \\
1 / 3 & 1 / 2 & 1 & 2 \\
1 / 5 & 1 / 3 & 1 / 2 & 1
\end{array}\right],
$$

whose maximum eigenvalue is $\lambda_{\max }=4.014521$ and the corresponding normalized criteria weight vector is $W=(0.4829,0.2720,0.1570,0.0882)^{T}$.

\subsection{Definition of assessment grades and acquirement of assessment data}

The following set of assessment grades has been defined for the four criteria by the British Highways Agency:

$$
\mathrm{G}=\{\text { High, Medium, Low, None }\}=\{\mathrm{H}, \mathrm{M}, \mathrm{L}, \mathrm{N}\} \text {. }
$$

For simplicity, we will use the above same set of assessment grades for all the four criteria in this illustrative example.

Table 2 shows the distributed decision matrix for the 20 bridge structures, which are evaluated by 10 bridge safety experts, 15 functionality experts, 20 sustainability experts and 10 environment experts in terms of the four criteria, respectively.

\subsection{Solution of model (3) to generate local risk scores}

For the risk assessment data in Table 2, we solve model (3) for each of the four criteria to generate the local risk scores of the 20 bridge structures with respect to the four criteria. The results are shown in the columns 2-5 of Table 3.

\begin{tabular}{|c|c|c|c|c|c|c|c|c|c|c|c|c|c|c|c|c|}
\hline \multirow{3}{*}{$\begin{array}{l}\text { Bridge } \\
\text { structure }\end{array}$} & \multicolumn{16}{|c|}{ Assessment criteria } \\
\hline & \multicolumn{4}{|c|}{ Safety } & \multicolumn{4}{|c|}{ Functionality } & \multicolumn{4}{|c|}{ Sustainability } & \multicolumn{4}{|c|}{ Environment } \\
\hline & $\mathrm{H}$ & $\mathrm{M}$ & $\mathrm{L}$ & $\mathrm{N}$ & $\mathrm{H}$ & $\mathrm{M}$ & $\mathrm{L}$ & $\mathrm{N}$ & $\mathrm{H}$ & $\mathrm{M}$ & $\mathrm{L}$ & $\mathrm{N}$ & $\mathrm{H}$ & $\mathrm{M}$ & $\mathrm{L}$ & $\mathrm{N}$ \\
\hline BS1 & 8 & 2 & & & 10 & 3 & 2 & & 15 & 4 & 1 & & & 5 & 4 & 1 \\
\hline BS2 & 4 & 6 & & & 2 & 8 & 5 & & 12 & 3 & 5 & & & 6 & 4 & \\
\hline BS3 & 3 & 4 & 3 & & 3 & 7 & 4 & 1 & 5 & 7 & 8 & & 1 & 3 & 4 & 2 \\
\hline BS4 & & 4 & 6 & & 5 & 5 & 5 & & 6 & 8 & 5 & 1 & 2 & 3 & 5 & \\
\hline BS5 & & 3 & 7 & & 4 & 6 & 3 & 2 & 7 & 7 & 6 & & 3 & 4 & 2 & 1 \\
\hline BS6 & 1 & 4 & 4 & 1 & 6 & 5 & 4 & & 8 & 6 & 4 & 2 & 4 & 5 & 1 & \\
\hline BS7 & 2 & 3 & 5 & & 3 & 6 & 5 & 1 & 10 & 10 & & & 6 & 4 & & \\
\hline BS8 & 3 & 5 & 2 & & 2 & 11 & 2 & & 9 & 9 & 2 & & 7 & 3 & & \\
\hline BS9 & 4 & 5 & & 1 & 9 & 5 & 1 & & 4 & 10 & 6 & & 8 & 1 & 1 & \\
\hline BS10 & & 9 & 1 & & 8 & 7 & & & 5 & 10 & 4 & 1 & 5 & 4 & & 1 \\
\hline BS11 & 7 & 3 & & & 9 & 2 & 2 & 2 & 7 & 8 & 5 & & & 7 & 2 & 1 \\
\hline BS12 & 5 & 4 & & 1 & 7 & 4 & 4 & & 4 & 9 & 3 & 4 & 3 & 1 & 6 & \\
\hline BS13 & 6 & 2 & 2 & & 6 & 6 & 3 & & 1 & 9 & 8 & 2 & 4 & 4 & & 2 \\
\hline BS14 & 5 & & 5 & & 1 & 14 & & & 5 & 5 & 5 & 5 & 5 & 2 & 2 & 1 \\
\hline BS15 & & 8 & 1 & 1 & 12 & & 3 & & 8 & 9 & & 3 & 6 & & 3 & 1 \\
\hline BS16 & 1 & 6 & 2 & 1 & & 8 & 7 & & 14 & & 6 & & 7 & & & 3 \\
\hline BS17 & 3 & 3 & 4 & & & 6 & 8 & 1 & 7 & 9 & & 4 & 8 & 2 & & \\
\hline BS18 & 2 & 4 & 4 & & 3 & 7 & 5 & & 9 & 9 & 2 & & 1 & 7 & 2 & \\
\hline BS19 & 1 & 5 & 4 & & 5 & 2 & 8 & & 11 & 6 & 3 & & 4 & & 4 & 2 \\
\hline BS20 & 4 & 3 & 3 & & 7 & 3 & 4 & 1 & 10 & 8 & 2 & & & 5 & & 5 \\
\hline
\end{tabular}

Table 2 Risk assessment data for 20 bridge structures

Note: H stands for High, M for Medium, L for Low, and N for None. 
Table 3 Local and overall risk scores of the 20 bridge structures and their risk priority ranking

\begin{tabular}{|c|c|c|c|c|c|c|}
\hline \multirow{2}{*}{$\begin{array}{l}\text { Bridge } \\
\text { structure }\end{array}$} & \multicolumn{4}{|c|}{$\begin{array}{l}\text { Local risk scores } \\
\end{array}$} & \multirow[b]{2}{*}{$\begin{array}{l}\text { Overall risk } \\
\text { score }\end{array}$} & \multirow[b]{2}{*}{$\begin{array}{l}\text { Risk priority } \\
\text { ranking }\end{array}$} \\
\hline & $\begin{array}{c}\text { Safety } \\
(0.4829)\end{array}$ & $\begin{array}{c}\text { Functionality } \\
(0.2720)\end{array}$ & $\begin{array}{l}\text { Sustainability } \\
(0.1570)\end{array}$ & $\begin{array}{c}\text { Environment } \\
(0.0882)\end{array}$ & & \\
\hline BS1 & 1.0000 & 0.9359 & 1.0000 & 0.4537 & 0.9344 & 1 \\
\hline BS2 & 0.7778 & 0.5897 & 0.8750 & 0.4815 & 0.7158 & 7 \\
\hline BS3 & 0.6667 & 0.6218 & 0.6442 & 0.4815 & 0.6346 & 16 \\
\hline BS4 & 0.4444 & 0.7051 & 0.6875 & 0.5741 & 0.5649 & 19 \\
\hline BS5 & 0.4259 & 0.6538 & 0.7212 & 0.6574 & 0.5547 & 20 \\
\hline BS6 & 0.5093 & 0.7564 & 0.7404 & 0.7593 & 0.6348 & 15 \\
\hline BS7 & 0.5741 & 0.6090 & 0.8654 & 0.8889 & 0.6570 & 12 \\
\hline BS8 & 0.6852 & 0.6282 & 0.8173 & 0.9444 & 0.7133 & 8 \\
\hline BS9 & 0.7500 & 0.9103 & 0.6346 & 0.9815 & 0.7959 & 3 \\
\hline BS10 & 0.5370 & 0.8846 & 0.6683 & 0.8056 & 0.6758 & 11 \\
\hline BS11 & 0.9444 & 0.8590 & 0.7308 & 0.4907 & 0.8477 & 2 \\
\hline BS12 & 0.8056 & 0.7949 & 0.6058 & 0.6111 & 0.7541 & 5 \\
\hline BS13 & 0.8519 & 0.7692 & 0.5000 & 0.7222 & 0.7627 & 4 \\
\hline BS14 & 0.7407 & 0.6154 & 0.6010 & 0.7685 & 0.6872 & 10 \\
\hline BS15 & 0.5093 & 1.0000 & 0.7644 & 0.8056 & 0.7089 & 9 \\
\hline BS16 & 0.5463 & 0.4872 & 0.9231 & 0.8611 & 0.6171 & 18 \\
\hline BS17 & 0.6481 & 0.4551 & 0.7212 & 1.0000 & 0.6381 & 13 \\
\hline BS18 & 0.5926 & 0.6282 & 0.8173 & 0.5741 & 0.6359 & 14 \\
\hline BS19 & 0.5370 & 0.6667 & 0.8654 & 0.6481 & 0.6336 & 17 \\
\hline BS20 & 0.7222 & 0.7756 & 0.8462 & 0.4167 & 0.7293 & 6 \\
\hline
\end{tabular}

\subsection{Prioritization of bridge structures in terms of their overall risk scores}

Small overall risk score is always preferred. Therefore, high risk priorities should be given to those bridge structures with big overall risk scores. As can be seen from Table 3, BS1 has the biggest overall risk score because of its highest safety risk score and the highest sustainability risk score as well as high functionality risk score. So, it is ranked in the first place and should be given a top priority for maintenance. BS5 has the smallest overall score of the 20 bridge structures and is ranked in the last place. The overall risk priority ranking of the 20 bridge structures is BS1 > BS11 > BS9 $>$ BS13 $>$ BS12 $>$ BS20 $>$ BS2 $>$ BS8 $>$ BS15 $>$ $\mathrm{BS} 14>\mathrm{BS} 10>\mathrm{BS} 7>\mathrm{BS} 17>\mathrm{BS} 18>\mathrm{BS} 6>\mathrm{BS} 3>$ BS19 > BS16 > BS4 > BS5. Such a risk priority ranking may change with the relative weights of the four assessment criteria. So, if necessary, a sensitivity analysis about the weights of criteria can be conducted.

\section{Conclusions}

In this paper, we proposed a hybrid AHP/DEA methodology to evaluate bridge risks of hundreds or thousands of bridge structures. To avoid making a large number of pairwise comparisons, the proposed hybrid
AHP/DEA methodology only uses the AHP to determine the weights of criteria, linguistic assessment grades to assess bridge risks, DEA model with common weights to determine the scoring of the linguistic assessment grades, and the simple additive weighting method to aggregate the bridge risks under different criteria into an overall risk score of each bridge structure. The bridge structures can then be prioritized for maintenance in terms of their overall risk scores. A numerical example was investigated to illustrate the applications of the proposed hybrid AHP/DEA methodology. It was shown that the hybrid AHP/DEA methodology is easy to use, applicable to any number of decision alternatives, and particularly useful and effective to those complex MCDM problems with a large number of decision alternatives, where pairwise comparisons are certainly impossible to be made.

\section{Acknowledgement}

The work has been partially supported by the Research Project TIN2006-02121.

\section{References}

[1] T.L. Saaty, The Analytic Hierarchy Process. McGraw-Hill, New York, 1980.

[2] O.S. Vaidya and S. Kumar, Analytic hierarchy process: An overview of applications. European Journal of Operational Research, 169 (1):1-29, 2006. 
[3] A. Charnes, W.W. Cooper and E. Rhodes, Measuring the efficiency of decision making units. European Journal of Operational Research, 2(6):429-444, 1978.

[4] W.M. Bowen, Subjective judgements and data envelopment analysis in site selection. Computers, Environment and Urban Systems, 14 (2): 133-144, 1990.

[5] J. Shang and T. Sueyoshi, A unified framework for the selection of a Flexible Manufacturing System. European Journal of Operational Research, 85 (2): 297-315, 1995.

[6] L.M. Seifert and J. Zhu, Identifying excesses and deficits in Chinese industrial productivity (19531990): a weighted data envelopment analysis approach. Omega, 26(2): 279-296, 1998.

[7] X.S. Zhang and J.C. Cui, A project evaluation system in the state economic information system of China: An operations research practice in public sectors. International Transactions in Operational Research, 6 (5): 441-452, 1999.

[8] Z. Sinuany-Stern, A. Mehrez and Y. Hadad, An AHP/DEA methodology for ranking decision making units. International Transactions in Operational Research, 7 (2): 109-124, 2000.

[9] T. Yang and C. Kuo, A hierarchical AHP/DEA methodology for the facilities layout design problem. European Journal of Operational Research, 147 (1), 128-136, 2003.

[10] Y. Takamura and K. Tone, A comparative site evaluation study for relocating Japanese government agencies out of Tokyo, SocioEconomic Planning Sciences, 37(2):85-102, 2003.

[11] R.F. Saen, A. Memariani and F.H. Lotfi, Determining relative efficiency of slightly nonhomogeneous decision making units by data envelopment analysis: a case study in IROST. Applied Mathematics and Computation, 165 (2): 313-328, 2005.

[12] F.H. F. Liu and H.L. Hai. The voting analytic hierarchy process method for selecting supplier. International Journal of Production Economics, 97(3): 308-317, 2005.

[13] R. Ramanathan. Data envelopment analysis for weight derivation and aggregation in the analytic hierarchy process. Computers \& Operations Research, 33(5):1289-1307, 2006.

[14] T. Ertay, D. Ruan and U.R. Tuzkaya, Integrating data envelopment analysis and analytic hierarchy for the facility layout design in manufacturing systems. Information Sciences, 176(3):237-262, 2006.

[15] Y.J. Feng, H. Lu and K. Bi, An AHP/DEA method for measurement of the efficiency of R\&D management activities in universities. International Transactions in Operational Research, 11(2): 181-191, 2004.
[16] C.L. Hwang and K. Yoon, Multiple Attribute Decision Making: Methods and Applications, Springer, Berlin, 1981.

[17] British Highways Agency Value Management of the Structures Renewal Programme. Version 2.2, 2004. 